\title{
The decline in incidence of acute intussusception in childhood in north-east Scotland
}

\author{
J. E. POLLET AND G. HEMS
}

From the Department of Surgery and the Department of Community Medicine, University of Aberdeen

SUMMARY The records have been studied of 77 cases of acute intussusception in children which occurred in Aberdeen City, Aberdeenshire, and Banffshire during the 10 years 1967-76. There has been a decrease in age-specific incidence of about a third since a previous study in the same region was carried out between 1950 and $1959 .^{1}$ The decline in rates is greater for rural areas than for Aberdeen City and it is more marked for girls than for boys.

The north-east of Scotland is a suitable area for epidemiological studies. It has a stable population of about 400000 and all children with surgical emergencies are treated at the Royal Aberdeen Children's Hospital. About half the population reside in an urban area (Aberdeen City) and the remainder in a predominantly rural area (Aberdeenshire and Banffshire). The surgical consultants at the Royal Aberdeen Children's Hospital had noticed that fewer cases of acute intussusception were appearing and this decrease was greater than the decline in children of the appropriate age groups, which implied a decline in incidence. This was tested by comparing numbers of cases during 1967-1976 with those observed in the same area a decade earlier by Steyn and Kyle. ${ }^{1}$

\section{Methods}

Cases of intussusception were identified from the Scottish Home and Health Department's computer-assisted inpatient data records and by thorough searches of the $x$-ray department's records and theatre operating books for the 10 years 1967-1976. Cases were included only if the child's mother resided permanently in Aberdeen City, Aberdeenshire, or Banffshire.

Populations were estimated from annual reports of the Registrar General, Scotland, and from census reports where applicable. Between 1973 and 1974 boundaries were altered because of reorganisation of local government and these alterations were taken into account.

In the previous study by Steyn and Kyle, ${ }^{1}$ incidence rates for 1950-1959 had been expressed as cases (all ages) per 1000 live births. For comparison with the present study it was necessary to calculate age-specific incidence rates. Unfortunately detailed data on population sizes were not available. The size of the population $0-11$ months was estimated as the $\$$ number of live births, recorded each year for the $\vec{E}$ area. For older children, population sizes were $\vec{N}$ estimated as means of the sizes in the census year 웅 1951 and 1961.

\section{Results}

Seventy-seven cases of acute intussusception we identified in the 10 years studied. Fifty-six $(73 \%)$ were male and the age distribution is given in Table 1 . Only $37(48 \%)$ were under one year old. The youngest patient was two months old and the eldest 11 years; the modal age was four to five months, at which age $13(17 \%)$ cases were identified. Twenty-four out of $56(43 \%)$ of the males were under one year and 13 out of $21(62 \%)$ of the females.

Table 1 Age distribution of 77 cases of acute intussusception

\begin{tabular}{lcc}
\hline & Age & No. of cases \\
\hline Months & $2-3$ & 5 \\
& $4-5$ & 13 \\
$6-7$ & 7 \\
$8-9$ & 7 \\
Years & $10-11$ & 5 \\
& & \\
& 1 & 14 \\
& 2 & 9 \\
& 3 & 7 \\
4 & 2 \\
& 5 & 3 \\
6 & 1 \\
7 & - \\
8 & 2 \\
9 & 1 \\
& 10 & 1 \\
\hline
\end{tabular}


The quarterly distribution by ages under and over one year is given in Table 2. The difference in the distributions is highly significant $\left(\chi^{2}=25 \cdot 4\right.$, df 3$)$ but the winter quarter contributes $17 \cdot 2$ to $\chi^{2}$, indicating that the difference between the age groups is concentrated almost entirely in this quarter. It also shows that the infants have a deficiency in this quarter and the children aged over one year a large surplus.

Table 2 The quarterly distribution by ages under and over one year

\begin{tabular}{llllll}
\hline Age & Spring & Summer & Autumn & Winter & Total \\
\hline $0-1$ & 12 & 13 & 10 & 2 & 37 \\
$1-11$ & 9 & 5 & 5 & 21 & 40 \\
& & & & & \\
$\chi^{2}$ & 0.75 & 4.9 & 2.5 & $17 \cdot 2$ & \\
df & 1 & 1 & 1 & 1 & \\
P & NS & $<5 \%$ & NS & $<0 \cdot 1 \%$ & \\
\hline
\end{tabular}

The urban/rural distribution by sex and by age under and over one year is shown in Table 3. The proportions under one year were $46 \%$ for urban males, $38 \%$ for rural males, $46 \%$ for urban females and $87 \%$ for rural females. These differences were not significant.

Table 3 Urban/rural distribution by sex and by age under and over one year (1967-1973)

\begin{tabular}{lllll}
\hline & & \multicolumn{2}{l}{ Ages } & \\
\cline { 3 - 5 } $\begin{array}{l}\text { Area of } \\
\text { residence }\end{array}$ & Sex & $\begin{array}{l}\text { Under } \\
\text { one year }\end{array}$ & $\begin{array}{c}1-11 \\
\text { years }\end{array}$ & All ages \\
\hline Urban & M & 16 & 19 & 35 \\
& F & 6 & 7 & 13 \\
& Both sexes & 22 & 26 & 48 \\
Rural & M & 8 & 13 & 21 \\
& F & 7 & 1 & 8 \\
& Both sexes & 15 & 14 & 29 \\
All areas & M & 24 & 32 & 56 \\
& F & 13 & 8 & 21 \\
& Both sexes & 37 & 40 & 77 \\
\hline
\end{tabular}

Mean annual incidence rates for six age groups are shown in Table 4. Rates were highest during the first year of life and declined steeply thereafter. Rates for females were approximately half those for males, and decline similarly with age.

When incidence rates for 1967-1973 were compared with rates from 1950-1959 they appeared to have declined by about a third. During the decade 1950-1959, 145 cases were observed ${ }^{1}$ compared with the 99 expected if rates observed during 1967-1973 prevailed. The decline was greater for
Table 4 Mean annual incidence rates per 1000 population for six age groups by sex (1967-1973)

\begin{tabular}{lll}
\hline $\begin{array}{l}\text { Age groups } \\
\text { (years) }\end{array}$ & $M$ & $F$ \\
\hline $0-1$ & 0.96 & 0.47 \\
$1-2$ & 0.46 & 0.11 \\
$2-3$ & 0.25 & 0.14 \\
$3-5$ & 0.15 & 0.02 \\
$5-10$ & 0.04 & 0.01 \\
\hline
\end{tabular}

females ( 25 cases expected, $43 \%$ of 58 observed in 1950-1959) than for males ( 74 cases expected, $85 \%$ of 87 cases observed). Also, the decline was greater for cases aged under one year (45 cases expected, $58 \%$ of 77 cases observed) than for cases aged one to 11 years (54 cases expected, 79\% of the 68 cases observed).

The most reliable data were for ages under one year, with populations based upon annual numbers of births. Table 5 shows the rates for males and females in the two 10 -year periods.

Table 5 Annual incidence rates per 1000 for infants by sex in 1950-1959 compared with 1967-1973

\begin{tabular}{llllll}
\hline Sex & $1950-59$ & $1967-73$ & $x^{2}$ & $d f$ & $P$ \\
\hline M & 1.3 & 0.96 & 5.6 & 1 & $<0.05$ \\
F & 1.0 & 0.47 & 3.7 & 1 & $<0.05$ \\
\hline
\end{tabular}

The decline in incidence was greater for the rural area than for Aberdeen City. Using rates observed for the period 1967-1973, 35.5 cases would have been expected in the rural area during 1950-1959, only $41 \%$ of the 87 cases observed, while in Aberdeen City the number of cases $(60 \cdot 1)$ expected equalled approximately the number observed (58). When these changes between the two 10-year periods were analysed separately for males and females, the decline in rates for females was greater than for boys in rural as well as urban areas.

\section{Discussion}

This study has shown a significant decline in the incidence of acute intussusception in the north-east of Scotland during the 1960 s. The reduction is most marked in three groups of children: those living in rural areas; females; and those aged under one year. It seemed unlikely that the low incidence was a spurious result of under-reporting because cases identified from $x$-ray department records, and also from operating theatre books, corresponded closely with those retrieved from the Scottish Home and Health Department's inpatient computer-assisted data. 
Cases aged under one year and those who were older appeared to be two different groups. For the younger cases, age appeared to have a greater effect on incidence than the quarter of the year. By contrast, season had a marked effect on incidence among children over one year old. The deficiency in infants in the winter quarter is not explicable and perhaps exaggerates the apparent statistical significance, but the surplus in children over one year of age in the winter quarter is impressive.

With population data becoming available in increased detail, incidence should be expressed as age-specific rates and not as cases per 1000 live births. This poor statistical measure has been used by many authors to compare the variations in incidence in different parts of the British Isles. ${ }^{1-8}$.In the present study, when results for the earlier and later periods were compared, expressing incidence as cases per 1000 live births could have been misleading because rates were increasing during the early period, but declined by about a fifth during the later one.

We thank Mr. J. Kyle and Mr. J. H. Steyn for the use of some of their data; Mr. P. F. Jones, Mr. S. S. Miller, and Mr. A. I. Davidson for permission to study their patients; and particularly Mr. Davidson for initiating this study.

Reprints from J. E. Pollet, Senior Registrar in General Surgery, Department of Surgery, University of Aberdeen, Foresterhill, Aberdeen AB9 2ZD.

\section{References}

${ }^{1}$ Steyn J, Kyle J. Epidemiology of acute intussusception. $\mathrm{Br}$ Med J 1961; 1: 1730-32.

${ }^{2}$ Morrison B, Court B. Acute intussusception in childhood. Br Med J 1948; 1: 776-80.

${ }^{3}$ Spence J, Court D. Acute intussusception in childhood. Br Med J 1950; 2: 920-1.

${ }^{4} \mathrm{Kyll}$ J. Acute intussusception: review of 200 cases. Ulster Med J 1954; 23: 117-23.

${ }^{5}$ MacMahon B. Data on aetiology of acute intussusception in childhood. Am J Hum Genet 1955; 7: 430-38.

${ }^{6}$ Court D, Knox G. Incidence of intussusception in Newcastle children. $\mathrm{Br}$ Med J 1959; 2: 408-9.

${ }^{7}$ Strang $R$. Intussusception in infancy and childhood: a review of 400 cases. Br J Surg 1959; 46: 484-95.

${ }^{8} \mathrm{Smith}$ IM. Incidence of intussusception and congenit $\bar{P}$ hypertrophic pyloric stenosis in Edinburgh children. $B$ Med J 1960; 1: 551. 